
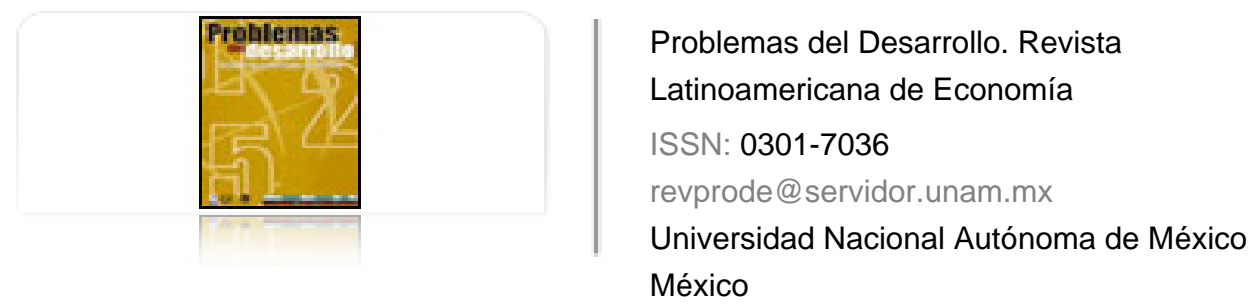

Chapoy Bonifaz, Alma

El dólar estadounidense: el impacto de sus fluctuaciones

Problemas del Desarrollo. Revista Latinoamericana de Economía, vol. 35, núm. 136, 2004, pp. 27-47

Universidad Nacional Autónoma de México

Distrito Federal, México

Disponible en: http://www.redalyc.org/articulo.oa?id=11825946003

Cómo citar el artículo

- Número completo

- Más información del artículo

Página de la revista en redalyc.org

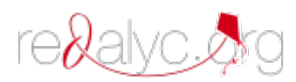

Sistema de Información Científica

Red de Revistas Científicas de América Latina, el Caribe, España y Portugal Proyecto académico sin fines de lucro, desarrollado bajo la iniciativa de acceso abierto 


\title{
EL DÓLAR ESTADOUNIDENSE: EL IMPACTO DE SUS
}

\section{FLUCTUACIONES}

\begin{abstract}
Alma Chapoy Bonifaz*
\end{abstract}
Fecha de recepción: 12 de abril de 2004. Fecha de aprobación: 14 de mayo de 2004.

\section{Resumen}

En este trabajo se pretende destacar la trascendencia que en las relaciones económicas internacionales tiene la cotización del dólar estadounidense, la principal divisa en el nivel mundial, analizando para ello la situación económica reciente de Estados Unidos, la Unión Europea, Japón y China. Aunque el dólar ha registrado variaciones en su valor desde el establecimiento de la flotación cambiaria, los niveles récord que ha alcanzado la deuda externa de EUA lleva a pensar que la economía mundial podría estar entrando en terrenos peligrosos, más allá de los grandes riesgos para los mercados financieros.

Palabras clave: tipo de cambio, sistema monetario y financiero internacional, relaciones internacionales, mercados de cambio, mercados financieros.

\section{Abstract}

This paper is concerned with showing the importance for international economic relations of exchange rates vis-à-vis the U.S. dollar — the leading currency worldwide- For this purpose, it analyzes the recent economic situation in the United States, the European Union, Japan and China. Although the dollar has seen changes in its value since the establishment of floating exchange rates, the record levels reached by U.S. external debt leads us to think that the world economy could be entering dangerous territory, going beyond the great risks faced by the financial markets.

Key terms: exchange rate, international monetary and financial systems, international relations, foreign exchange markets, financial markets.

* Investigadora titular del Instituto de Investigaciones Económicas (UNAM). La autora agradece el apo yo de los licenciados Víctor Medina y Alma Torres en el acopio de material bibliohemerográfico. Correo electrónico: gori@servidor.unam.mx 


\section{Résumé}

Cette étude prétend souligner la transcendance de la cotisation du dollar américain, la principale devise au niveau mondial, dans les relations économiques internationales, en analysant pour ce faire la situation économique actuelle des Etats-Unis, de l'Union Européenne, du Japon et de la Chine. Bien que la valeur du dollar ait enregistrée des variations depuis l'établissement $d u$ flottement des monnaies, les niveaux records qu'a atteint la dette externe des Etats-Unis conduit à penser que l'économie mondiale pourrait s'engager dans des domaines dangereux, bien au-delà des grands risques que pourraient courir les marchés financiers.

Mots-clés: taux de change, système monétaire et système financier international, relations internationales, marchés des changes, marchés financiers.

\section{Resumo}

Este trabalho, a partir de uma análise da situação econômica recente dos Estados Unidos, da União Européia, do Japão e da China, pretende destacar a transcendência, que nas relações econômicas internacionais, tem a cotação do dólar norte-americano, a principal divisa a nível mundial. Mesmo com o dólar registrando, após o estabelecimento da flutuação cambial, constantes variações de valor, os níveis recordes que alcançou a dívida externa dos EUA sugerem pensar que a economia mundial possa estar entrando em terrenos perigosos, o que pode ocasionar graves riscos para os mercados financeiros.

Palavras-chave: tipo de câmbio, sistema monetário e financeiro internacional, relações internacionais, mercados de câmbio, mercados financeiros. 


\section{Introducción}

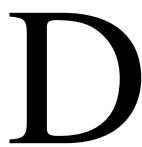

esde 1973, al generalizarse la flotación cambiaria, principalmente entre los países industrializados, el valor del dólar ha fluctuado considerablemente al alza y a la baja frente a otras monedas líderes y a las monedas de sus socios comerciales. Por su notable influencia en otras variables económicas, el tipo de cambio es el precio más relevante en cada economía, y el del dólar es también el más importante en la economía mundial.

El tipo de cambio — el precio de una moneda en términos de otra- entre las principales divisas fluctúa minuto a minuto, razón por la cual ese indicador sigue siendo una de las preocupaciones fundamentales de los encargados de manejar la economía en los diferentes países.

La interacción de particulares, empresas e instituciones financieras - que para realizar pagos internacionales compran y venden divisas en el mercado cambiario- es lo que determina los tipos de cambio. Noticias importantes e impredecibles, desde el punto de vista económico y político, circulan casi instantáneamente por todo el mundo, afectando de manera determinante las decisiones de quienes participan en el mercado cambiario.

Las variaciones en el valor del dólar, en términos de otras divisas clave, desempeñan un papel fundamental en EUA, y por el poder hegemónico de éste, en casi todo el mundo. Las expectativas acerca del valor futuro de esa divisa afectan desde las tasas de interés a corto plazo hasta las decisiones de inversión a largo plazo.

Bajo el sistema de Bretton Woods se daban importantes asimetrías. Una de ellas, en el proceso de ajuste: los países superavitarios difícilmente apreciaban sus monedas; en cambio, los deficitarios agotaban sus reservas y eran obligados a devaluar. El actual sistema de tipos de cambio flotantes ha mitigado este contraste pues las monedas se ajustan cuando las circunstancias cambian, excepto la divisa de EUA, pues este país suele seguir una política de negligencia benigna, dejando el ajuste a otros.

Como el fuerte déficit comercial estadounidense se atribuye en gran medida a la relativa debilidad de las economías de Europa y Japón, EuA busca que el ajuste recaiga en ellos, y los presiona para que modifiquen sus tipos de cambio y sus niveles de precios.

Esto lo puede hacer EuA en virtud de su poderío y del consiguiente fortalecimiento del dólar como principal moneda de reserva, ya que el euro y el yen se mantienen a considerable distancia, desempeñando un papel bastante más reducido en las relaciones económi- 
cas internacionales. Ello porque la importancia de una moneda en el sistema monetario internacional es reflejo de su posición en la economía mundial. Así, el dólar, el euro y el yen tienen una importancia acorde con el lugar que ocupan como núcleos de poder en el juego de fuerzas económicas internacionales.

Los países hegemónicos manejan sus asuntos de económías, y por ende los monetarios, en función de sus intereses, lo cual tiene repercusiones perjudiciales para los países subdesarrollados y emergentes; un ejemplo de ello se encuentra en la crisis financiera asiática (1997-1998). Por tanto, aunque aquí se hace énfasis en Estados Unidos, la Unión Europea, Japón y China, la situación que se plantea tiene consecuencias en la economía mundial en su conjunto.

Así pues, en este trabajo se pretende destacar la trascendencia que en las relaciones económicas internacionales tiene la cotización del dólar, la principal divisa en el nivel mundial, analizando para ello la situación económica reciente de Estados Unidos (EUA), la Unión Europea (UE), Japón y China, y algunas de las medidas que se han propuesto para dar estabilidad al sistema monetario internacional.

\section{Evolución reciente de la economía estadounidense}

Entre 2001 y febrero de 2004, el dólar, la moneda dominante en el mundo, cayó 33\% frente al euro y $15 \%$ ante el yen (Platt, Global Finance, varias ediciones). Existen muchas explicaciones para esto, sin que pueda señalarse un factor decisivo; sin embargo, tres características de la economía estadounidense influyen de manera definitiva en ese fenómeno: $a$ ) déficit presupuestal (20\% del PIB); $b$ ) baja tasa de ahorro interno y $c$ ) déficit en cuenta corriente (500 mmd, 5\% del PIB); además, registra una deuda externa de 2 billones de dólares (FMI, 2003c).

Todo indica que seguirá registrándose una significativa declinación en el valor del dólar; se calcula que caerá entre 10 y $20 \%$ en 2004, lo que lo llevaría de 1.27 euros a 1.40 o 1.50 entre enero de 2004 y principios de 2005. Esta caída impondría severas tensiones al sistema financiero internacional y a la economía global.

En los años noventa la inversión se elevó en todo el mundo, pero en especial en EUA, en virtud de la fortaleza económica de esa nación. ${ }^{1}$ Una caída en los ahorros estadounidenses provocó el abultado déficit en cuenta corriente. ${ }^{2}$

Antes de la crisis financiera asiática, EuA tenía un déficit en cuenta corriente manejable (150 mmd); posteriormente se permitió que el dólar se apreciara, que el déficit en cuenta

Cabe señalar que según algunos autores (Bowles, 1989) hay un proceso de debilitamiento de la economía estadounidense desde los años setenta.

2 De acuerdo con Edwin M. Truman del American Enterprise Institute (AEI), el nivel sostenible del déficit en cuenta corriente estaría entre 1 y $3 \%$ del Prb. 
corriente llegara a un muy alto nivel y que se viera seriamente perjudicado parte del sector manufacturero de EUA. En 2001 se inició un ciclo a la baja del dólar.

A pesar de esos problemas, el dólar mantiene su preeminencia a nivel mundial, tal como ha sucedido en ocasiones anteriores cuando se ha registrado una baja en el valor de esa moneda.

Existen varias razones que explican la primacía del dólar en el nivel mundial: a) en el país emisor, EUA, se genera el $25 \%$ de la producción mundial y gran parte del comercio internacional; $b$ ) actualmente euA está creciendo más rápidamente que la mayoría de sus socios comerciales; c) el grueso de las materias primas, incluyendo el petróleo, se cotizan en dólares; $d$ ) mientras más inestable es la situación económica en un país, más se prefieren los dólares a la moneda local; e) 65\% de las reservas monetarias internacionales está en dólares; $f$ ) aproximadamente el $50 \%$ de los dólares en circulación, están fuera de EuA; y no menos importante, $g$ ) EuA posee el aparato militar más poderoso del mundo, la prueba más reciente de ello se tiene en el caso de la invasión a Irak (FMI, 2003).

Abundando sobre los puntos e) y $f$ ), en 1971, cuando cayó el sistema de Bretton Woods, el mundo tenía 134 mil millones en reservas monetarias internacionales fuera de EUA. En septiembre de 2002, esas reservas ascendían a 1.8 billones, la mayoría en dólares. Más de las dos terceras partes (1.27 billones) de los 1.8 billones de reservas fuera de EUA está en poder de cinco países: Japón (520 mmd), China (330 mmd), Hong Kong (114 mmd), Taiwan (175 mmd) y Corea del Sur (128 mmd) (FMI, IFS).

Estas circunstancias seguramente determinarán que pese a su depreciación, el dólar no vea amenazada su posición hegemónica.

Durante la presidencia de Bush (hijo), el presupuesto de EUA ha pasado de presentar considerables superávit a registrar grandes déficit, lo que es causa de creciente preocupación, a pesar de otros buenos resultados económicos. ${ }^{3}$ Un déficit presupuestal como el de 2003 (375 mmd y más de 500 mmd para el ejercicio 2004) (FMI, 2003) seguramente perjudicará la capacidad de expansión de la economía. De continuar dicho déficit (lo cual es de esperarse, entre otras cosas por los crecientes gastos militares con motivo de la invasión a Irak), la inversión irá a otros países, se erosionará el aumento de la productivi-

3 Después de un crecimiento del PIB de 0.3\% en 2001, de 2.2\% en 2002, en 2003 creció 3.1\% (8.2\% en el tercer trimestre, el mayor avance en dos décadas). El FMI prevé que en 2004 el PIB de EUA crecerá $4 \%$, el doble de lo previsto en la eurozona. El mejor desempeño de la economía estadounidense se debe en buena medida a la aplicación de políticas fiscales y monetarias expansivas que alentaron el consumo y la inversión, en particular la destinada a ramas de alta tecnología. La mayor actividad económica y un dinámico crecimiento de la productividad alentaron las utilidades empresariales: el índice Nasdaq acumuló un alza de 50\% en 2003 y las utilidades operativas de las empresas tecnológicas incluidas en el índice Standard \& Poor's subieron 150\%. Cabe señalar que no obstante, a fines de enero de 2004, el índice Nasdaq todavía estaba 59\% por debajo del máximo histórico alcanzado en 2000. La productividad de la economía estadounidense subió 2.2\% en 2003, con un repunte extraordinario de $9.5 \%$ en el tercer trimestre, el más importante en veinte años (FMI, 2004a). 
dad del país y aumentará el déficit en cuenta corriente, sustrayendo más ahorro mundial e incrementando el riesgo de desorden en los mercados financieros.

Los déficit comercial y en cuenta corriente y la deuda externa son un serio problema para EUA y la economía mundial. Este país depende de la inversión extranjera para financiar esos desequilibrios; si los inversionistas extranjeros pierden la confianza en la economía estadounidense y dirigen sus inversiones a otros países, esta nación estaría en dificultades.

Una caída abrupta del dólar podría ocurrir si el gobierno de EUA —en vista de que 2004 es un año electoral - en vez de adoptar las medidas pertinentes, hiciera un gran recorte de impuestos. Con ello se repetiría la combinación de recortes fiscales y recesión de principios de los ochenta. La restricción fiscal en la administración de Clinton fue un importante elemento para producir la tasa de desempleo más baja en treinta años, crecimiento de la productividad y cambio de déficit a grandes superávit fiscales. En las condiciones actuales sería conveniente un modesto recorte de impuestos (o incluso ningún recorte), esto es, aplicar una política fiscal relativamente restrictiva, hacer inversiones razonables y mantener una buena parte del superávit para seguir pagando y reduciendo la deuda (Sarbanes, 2001).

En febrero de 2004 Greenspan aconsejó hacer recortes en los gastos gubernamentales, pues en su opinión reducir el déficit fiscal a mediano plazo y un fuerte crecimiento de los socios comerciales ayudarían a bajar el déficit en cuenta corriente, siempre y cuando se fortalezca el ahorro nacional.

Con una inflación próxima a los mínimos de posguerra y tasas de interés cercanas a cero, lo aconsejable es asegurar una recuperación sólida. EUA tiene necesidad de hacer sus importaciones menos atractivas y sus exportaciones más competitivas. El dólar más débil está logrando eso y no parece estar estimulando la inflación ${ }^{4} \mathrm{o}$ afectando los mercados de valores. En el último trimestre de 2003, el volumen de las exportaciones de EuA aumentó a una tasa anual de 19\%, y el de sus importaciones, a sólo $11 \%$ en igual periodo. Al hacer sus manufacturas más competitivas, se crearían empleos y se consolidaría el crecimiento.

Así pues, el problema para el gobierno de euA es lograr una declinación en el valor del dólar, pero evitando una caída excesiva. El mejor escenario sería un suave aterrizaje; sin embargo, en 2003, el dólar bajó casi 22\% en relación al euro y $12 \%$ frente al yen (Scherer, 2004), lo que no puede considerarse una declinación gradual; por ello se teme que los inversionistas globales pierdan la confianza en los mercados financieros estadounidenses.

Con una economía en rápido y fuerte crecimiento en los años noventa, muchos inversionistas extranjeros establecieron sucursales en EUA, adquirieron empresas o compraron acciones y bonos estadounidenses, lo que dio por resultado elevar el valor del dólar. Ahora bien, como el FED ha bajado las tasas de interés en EUA, los inversionistas a corto plazo pueden cambiar sus tenencias denominadas en dólares a valores europeos,

4 Los incrementos en la productividad han evitado aumentos de precios, a pesar de la reactivación económica. 
japoneses o de los mercados emergentes. Así pues, el continuo flujo de capital extranjero a EUA ayuda a que no se incrementen las tasas de interés y a que se mantenga el crecimiento de la economía; pero los inversionistas extranjeros pueden deshacerse de sus tenencias en dólares y ya no seguir financiando los déficit de EuA.

Sin embargo, las tasas de interés podrían subir ${ }^{5}$ para seguir atrayendo capitales extranjeros, ya que una parte creciente del déficit externo de EuA está financiado por inversiones de cartera que, a diferencia de la inversión extranjera directa, fácilmente pueden salir del país. En combinación con el comportamiento de manada de los especuladores, esto puede causar volatilidad en los mercados cambiarios. Empero, cabe señalar que en mayo de 2004 se registra una recuperación en el valor del dólar estadounidense.

Tasas de interés más altas, para asegurar que los países acreedores sigan apoyando al dólar, harían más costoso financiar el déficit presupuestal de la nación, y perjudicarían los resultados del mercado de valores. El mercado accionario de EuA se elevó casi $25 \%$ en 2003 e inició 2004 con tendencia ascendente (Scherer, 2004). La mayoría de los analistas del mercado de bonos no ven signos de que vayan a retirarse los inversionistas extranjeros.

El FMI señala que aunque el gasto estadounidense creó el actual crecimiento económico sólido en EuA, con sus consecuencias positivas para la economía global, ahora hay que pagar el precio y reequilibrar los déficit gemelos. Es preocupante que el FMI pronostique una ulterior declinación en el valor del dólar: "Aunque el ajuste del dólar podría ocurrir gradualmente en un periodo prolongado, los posibles riesgos globales de un ajuste cambiario desordenado, especialmente para los mercados financieros, no pueden pasarse por alto" (FMI, 2003a).

Conviene aquí detenerse a analizar el desequilibrio externo de EUA. Al iniciarse los años setenta, EUA era el mayor acreedor del mundo. Gobiernos e individuos extranjeros debían a EuA más de lo que éste les debía a ellos. Pero los persistentes déficit comercial y en cuenta corriente erosionaron gradualmente su posición acreedora e hicieron de eUA el mayor deudor del mundo. Varios años de déficit han dejado a ese país con una deuda externa cercana a 2 billones de dólares, esto es, más de 20\% del PIB estadounidense, y se pronostica que llegue a $40 \%$ en 2007. Esto es algo sin precedente, tratándose del país central en la economía mundial. El crecimiento de la deuda externa de EUA significa que cada año un mayor porcentaje de los ingresos de la nación se destinarán al servicio de la deuda en vez de utilizarse para elevar el nivel de vida de los estadounidenses. Ese desequilibrio externo es insostenible.

Desde hace más de veinte años, los estadounidenses han estado consumiendo más de lo que producen e invirtiendo más de lo que ahorran. En gran medida, lo que se pide prestado en el exterior no se invierte; simplemente se consume.

5 De hecho en mayo de 2004 el Sistema de la Reserva Federal anunció que se tenía la intención de elevar en breve la tasa de interés. 
Cuando los préstamos del exterior se aplican a inversiones productivas, estas generan los recursos necesarios para cubrir el pago de intereses y del principal; así no existe mayor problema. Pero el hecho de que el déficit estadounidense en cuenta corriente se amplíe al tiempo que el ahorro interno declina, significa que el endeudamiento externo financia el consumo en vez de la inversión. De ahí los déficit comercial y en cuenta corriente. Para disminuirlos, EuA tendrá que adoptar medidas que estimulen el ahorro interno.

La decisión de invertir en vez de consumir es un factor fundamental; al invertir, un país pone las bases de la producción futura que permite pagar el préstamo e incluso elevar el nivel de vida interno. Por ello es preocupante que el actual déficit en cuenta corriente de EUA sea consecuencia, cada vez más, de bajas tasas de ahorro y no de altas tasas de inversión como en los años noventa.

Cínicamente algunos funcionarios estadounidenses señalan que el déficit en cuenta corriente estadounidense está financiado casi totalmente en moneda local, con costos financieros insignificantes, por lo que la posición deudora neta de EuA no presenta un riesgo crediticio. Además, la gente voluntariamente decide invertir en esta nación EUA al considerar que allí las oportunidades de inversión son mejores que las existentes en sus propios países; esto hace que EUA no se sienta presionado a reducir su déficit comercial. Los ahorros mundiales seguirán dirigiéndose a este territorio hasta que los inversionistas tengan otras opciones igualmente atractivas; la eurozona poco a poco está ganando terreno en este aspecto.

Algunos expertos como Walter (2001) consideran que el mercado estadounidense sigue siendo muy atractivo, debido a la estabilidad del gobierno y al poderío de ese país, por lo que no cree que los inversionistas internacionales dejen de mandar su capital a EUA. Sin embargo, hay que tomar en cuenta el carácter insostenible económica y políticamente de los déficit en cuenta corriente y de la deuda externa.

\section{La Unión Europea y el papel internacional del euro}

La eurozona, con 307 millones de habitantes, es una gran potencia económica que representa $15 \%$ del PIB mundial (frente a $20 \%$ de EUA y $10 \%$ de Japón), y $20 \%$ del comercio mundial. Sin embargo, el nivel de productividad es menor en Europa que en EUA (Banco Mundial, 2003).

El euro ha fluctuado en forma importante en relación con el dólar desde 1999. Se depreció 16\% entre 1999 y 2001 para luego apreciarse como reflejo de la depreciación del dólar. La cotización inicial del euro no se justificaba ni sobre bases cíclicas ni estructurales; tenía que haber una corrección. Pero de estar sobrevaluado, pasó a subvaluarse hasta casi 80 centavos de dólar. Desde mediados de 2001, al desacelerarse la economía estadounidense, el euro empezó a experimentar una apreciación.

A la eurozona corresponde el $25 \%$ del comercio exterior de euA (excluido el petróleo). El euro podría llegar a apreciarse hasta 1.50 dólares, lo que reduciría el crecimiento del 
PIB en la eurozona en uno o dos puntos porcentuales durante dos años. Desgraciadamente existe poco margen de maniobra para hacer frente a tal situación; habría que aplicar una política monetaria menos restrictiva. Los efectos sobre los precios y la riqueza de un euro fuerte podrían impulsar la realización de reformas estructurales y la creación de estructuras económicas flexibles, tal como lo desea EUA.

De acuerdo con los organismos financieros internacionales y con el gobierno de EUA, aunque la fortaleza del euro reducirá las exportaciones de la eurozona y alejará sus perspectivas de crecimiento, las dificultades económicas de Europa no se deben a su moneda. Tampoco derivan de la política monetaria del Banco Central Europeo (BCE), aunque la moneda única y la falta de movilidad laboral inhiben el ajuste ante shocks asimétricos en la eurozona. Más bien, los problemas fiscales y regulatorios limitan el crecimiento potencial. Para impulsar el crecimiento de la producción y el empleo, es necesario realizar reformas estructurales tendientes a flexibilizar la economía de la eurozona y a impulsar el avance en ciencia y tecnología.

El objetivo de las políticas fiscal y monetaria no debe ser subvaluar al euro, ya que los problemas estructurales no se resuelven con política monetaria. En vez de eso, la política fiscal debe estimular el crecimiento, y la política monetaria debe tender a alcanzar la estabilidad de precios. Los funcionarios estadounidenses afirman que la reforma estructural y medidas macroeconómicas que fortalezcan la demanda interna, aunadas a la creación de un verdadero mercado único, con movilidad de la fuerza de trabajo y prácticas laborales flexibles, son más importantes que el tipo de cambio del euro para alcanzar el pleno potencial de crecimiento en la región.

El Pacto de Estabilidad y Crecimiento (PEC) ${ }^{6}$ inhibe el ajuste con una política físcal nacional contraccionista, mientras la autoridad monetaria recae en el BCE, institución supranacional. El BCE apoya la reforma estructural, pero el canciller alemán Gerhard Schroeder pide medidas para depreciar al euro. El BCE podría hacer bajar el valor del euro, como quiere Schroeder, recortando las tasas de interés; pero el mandato de esa institución es asegurar la estabilidad de precios. ${ }^{7}$ La rígida economía europea es más proclive a la inflación que la estadounidense; de este modo, un recorte en la tasa de interés

6 El PEC entró en funcionamiento el 1 de enero de 1999, al arrancar la tercera etapa de la unión económica y monetaria (UEM) europea. Obliga a los países participantes a realizar un esfuerzo permanente por alcanzar el superávit en las cuentas públicas y a respetar el tope para el déficit público (3\% del PIB) impuesto por el Tratado de Maastricht. Este pacto impone sanciones financieras al país cuyo déficit público rebase por dos años consecutivos el 3\% del PIB; sin embargo, precisa también cuándo un déficit superior a ese porcentaje puede no considerarse excesivo debido a circunstancias excepcionales y temporales (Chapoy, 1998b).

$7 \quad$ El tratado de Maastricht hace de la estabilidad de precios el objetivo principal del всE. Pero una vez alcanzada esa meta, el tratado señala que el все debe apoyar las políticas generales de la uE tendien tes a la creación de empleo y al logro del crecimiento económico. La política monetaria debe poner atención en el crecimiento. 
podría impulsar al alza la inflación. Europa ya ha hecho cambios en la política macroeconómica y microeconómica, que podrían contribuir a un más rápido crecimiento.

La aparición de la eurozona ejerce gran atracción sobre los inversionistas globales a expensas de EUA, algo peligroso tomando en cuenta el elevado monto de la inversión europea que llegó a este país en los últimos años. ${ }^{8}$ A medida que Europa sea más atractiva para los inversionistas, se irá dificultando financiar el déficit en cuenta corriente estadounidense; no se prevén retiros masivos de inversiones en dólares, pero crecen las inversiones en euros.

Desde 1999, el uso internacional del euro ha ido ganando terreno, consolidándose como la segunda moneda internacional, aunque a considerable distancia del dólar; $14.6 \%$ de las reservas monetarias internacionales están en euros, dos puntos arriba de cuando ocurrió su lanzamiento en 1999. Lo anterior revela que aumenta gradualmente la confianza en el euro por parte de los agentes privados no residentes. La participación del euro en la deuda pendiente en obligaciones internacionales alcanzó 30\% en junio de 2003 (9 puntos más que en junio de 1999) contra 44\% para el dólar (3 puntos a la baja en relación con junio de 1999). El euro representó $25 \%$ de las obligaciones internacionales a pagar por los bancos a fines de 2002 (5 puntos más que a mediados de 1999), contra 53\% para el dólar ( 2 puntos a la baja en relación a junio de 1999) (Micco, Stein y Ordóñez, 2003). Así pues, el euro ha ayudado a profundizar la integración económica europea y está adquiriendo creciente importancia en el mercado de bonos global y como moneda internacional.

\section{Las monedas asiáticas. Papel internacional del yen}

\section{a) Japón}

La gran inversión japonesa en el este y sudeste asiáticos continúa alentando los rumores de un eventual bloque del yen. Sin embargo, éste es sólo una moneda internacional en potencia, que incluso ha visto decrecer su participación en las reservas internacionales de divisas: de 7.9\% en 1994 a 4.5\% en 2002 (FMI, 2003). Eisuke Sakakibara (2001), con su experiencia como ex viceministro de finanzas de Japón, considera que a corto plazo "el yen no se internacionalizará, pues sólo una economía abierta puede apoyar a una moneda internacional".

La ASEAN $+3^{9}$ y los acuerdos swap para préstamos entre sus miembros podrían ser un primer paso hacia una especie de unión monetaria laxa. Por ahora, seguramente la ASEAN y otros países asiáticos seguirán vinculados al dólar, y en el futuro quizá a una canasta de

8 Los flujos de IED europea a EuA tuvieron un nivel promedio en 1998 2002, de $156.3 \mathrm{mmd}$, tres veces el promedio de 1994 1997 (50.1 mmd). En cambio las IED estadounidenses en Europa no llegaron a duplicarse, pues entre ambos periodos pasaron de 43.8 a $77 \mathrm{mmd}$. Esas cifras revelan que entre 1998 y 2000, la introducción del euro y el auge de los mercados accionarios contribuyeron al auge de las fusiones adquisiciones hacia EUA.

9 Los diez miembros de la Asociación de Naciones del Sureste de Asia (ASEAN) son: Indonesia, Tailandia, Singapur, Malasia, Brunei Darussalam, Filipinas, Vietnam, República Democrática Popular de Laos, Myanmar y Camboya; más China, Corea del Sur y Japón. 
monedas que incluya al dólar, al euro y eventualmente al yen. Gran parte de Asia está básicamente en la zona del dólar, por lo que Sakakibara encuentra todavía "remota la posibilidad de una unión monetaria asiática" en el mediano plazo. Empero, el comercio intrarregional crece con rapidez; ello y la competencia china podría llevar a relaciones más estrechas entre las monedas asiáticas.

A este respecto, conviene mencionar que los participantes en un seminario regional ${ }^{10}$ (Singapur, enero de 2004) consideraron que EuA, cuya participación en la economía global ha crecido enormemente en las pasadas tres décadas, al lado de China e India ${ }^{11}$ serán los motores del fuerte crecimiento de Asia y que el papel de Japón irá disminuyendo. Los participantes se centraron en la necesidad de intensificar la integración regional; concretamente, en una mayor demanda intrarregional, aumentos en la productividad y una posible coordinación regional en cuanto a la administración de los tipos de cambio. Asimismo, se puso de manifiesto el interés en aprender de la eurozona, la secuencia de medidas adoptadas en las distintas esferas de integración regional (comercio, inversión y unión monetaria) antes de proceder a la plena integración.

La década de estancamiento de la economía japonesa condujo a un gradual debilitamiento del yen que hace más competitivas las exportaciones en gran parte de Asia y desde luego en EUA y que podría incrementar las presiones sobre la industria estadounidense.

El Banco de Japón ha adoptado un programa de expansión monetaria, que ha hecho bajar las tasas de interés, declinar la tasa de deflación y lograr un crecimiento de $2.5 \%$ en el primer trimestre del año fiscal japonés, lo que indica que, superando previsiones, el país empieza a recuperarse. De enero a junio de 2003, el Banco de Japón gastó aproximadamente 50 mil millones de dólares en comprar bonos gubernamentales de EuA para estabilizar el yen. Esta intervención tuvo éxito porque mantuvo el tipo de cambio yen-euro acorde con las perspectivas de mayor crecimiento en Europa. En febrero de 2004, Japón volvió a intervenir en los mercados cambiarios.

Ante esto, EUA insiste en que las autoridades japonesas no deben permitir que las manipulaciones del tipo de cambio sean un sustituto de la reforma económica; además, en Japón es muy bajo el efecto que tienen sobre los precios internos las modificaciones en los tipos de cambio. Tasas de interés más bajas y una política monetaria laxa sugieren una ulterior declinación en el valor del yen en relación al dólar y al euro.

Para permitir la apreciación del yen, como desea EuA, Japón tendría que adoptar decisiones políticas difíciles, pues — además de las repercusiones en su economía—iría contra

10 Funcionarios de Filipinas, Indonesia, Malasia, Singapur, Tailandia, China y Japón.

11 Juntos concentran casi el $40 \%$ de la población mundial y el $20 \%$ de la producción mundial. En 1980, India era la quinta economía mundial y China la novena (según el pib de acuerdo a la paridad del poder adquisitivo). En 2001 China ya era la segunda (otros cálculos siguen colocando a Japón en esa posición), detrás de EuA e India la cuarta (FMI, 2004). 
los intentos que se han mencionado por coordinar en mayor medida los tipos de cambio con las economías del sudeste asiático, en el marco de la ASEAN+3.

Parte de los problemas de Japón derivan del hecho de que tiene una economía dual, con un sector dinámico, competitivo a nivel internacional, y una productividad que iguala o incluso supera a la de industrias comparables en EuA. Sin embargo, en los sectores más tradicionales — construcción, comercio al menudeo y cuidado de la salud — los niveles de productividad representan dos tercios de los estadounidenses. Estos sectores atrasados dependen mucho del apoyo y de los subsidios del sector público, y de leyes que limitan la competencia nacional y extranjera. Es por ello que Japón ha empezado a aplicar una política monetaria expansiva, pues la contraccionista ha favorecido a los sectores atrasados, en detrimento de los eficientes y modernos (Sakakibara, 2001).

Los inversionistas institucionales japoneses habían dejado de comprar valores estadounidenses ante el temor de un violento aterrizaje del dólar. Sin embargo, los bajos rendimientos sobre acciones y bonos en Japón sugiere que ellos eventualmente revertirían el curso y volverían a los mercados financieros de EUA. El temor al endaka (el yen en ascenso) está presente en Japón. En opinión de Sakakibara, 120 o 125 yenes por dólar es el nivel adecuado. En una espiral a la baja, el yen podría irse a 130 o incluso hasta 140.

\section{b) China}

Los principales problemas que enfrenta este país, además del bajo nivel de ingreso per capita y de la desocupación, ${ }^{12}$ son las fuertes entradas de capital, la notable expansión de los préstamos bancarios y el recalentamiento de la economía. Acorde con el gobierno estadounidense, Goldstein (FMI, 2003a: 367) sostiene que China debería permitir la libre flotación de su moneda (el renminbi o yuan) y abrir completamente la cuenta de capital; sabiamente, el gobierno chino se niega a hacerlo pues casi seguramente tras la apertura sobrevendrían problemas bancarios que podrían provocar una gran fuga de capitales.

Una mejor forma de resolver sus problemas sería vincular el tipo de cambio a una cesta con igual ponderación del dólar, del yen y del euro; revaluarlo entre 15 y $25 \%$ y ampliar la banda cambiaria de menos de $1 \%$ a 5 o $7 \%$. Una vez que el sistema bancario se fortaleciera, China quizá podría abrir la cuenta de capital y permitir la flotación del renminbi.

Por buenas razones, China se resiste a apreciar su divisa; hacerlo eliminaría cerca de medio millón de empleos en el sector exportador, que es el más intensivo en mano de obra,

12 China necesita crear entre 12 y 15 millones de nuevos trabajos cada año para mantener el paso con su crecimiento poblacional. Las áreas rurales están marginadas del actual auge del país, y una tercera parte de los habitantes de esas áreas está desempleada o subempleada (The Economist, 2004). En cuanto al PIB per capita, que en China fue de 1000 dólares en 2003, sitúa a ese país al nivel de Namibia, Guatemala y Marruecos, apenas a mitad del camino para convertirse en un país de ingreso medio (Banco Mundial, 2003). 
perjudicando las perspectivas de crecimiento y creando un enorme problema político. Por ello difícilmente China apreciará su tipo de cambio (FMI, 2003b:368).

Horst Koehler, cuando estaba a punto de dejar la dirección del FMI, se unió a los clamores de EuA y Japón para que China adopte una política cambiaria más flexible y permita la flotación del renminbi. Esa divisa está en un nivel casi sin cambio de 8.28 por dólar, para favorecer sus exportaciones. Los empresarios de EUA acusan a China de invadir su mercado con manufacturas baratas, lo que ha aumentado el déficit comercial y provocado la pérdida de millones de empleos en ese país.

En suma, los líderes chinos no quieren abandonar su política cambiaria ni los controles monetarios, pues consideran que el tipo de cambio fijo, los superávit presupuestales y las grandes reservas monetarias internacionales $(330 \mathrm{mmd}$ ), son los instrumentos para evitar crisis como las que sufrieron México y algunos países de Asia en los años noventa. ${ }^{13} \mathrm{El}$ desarrollo a largo plazo es causa de preocupación y permitir que la moneda se aprecie haría que las tasas de crecimiento económico bajaran. China lucha contra presiones deflacionarias ${ }^{14}$ y con altos niveles de deuda interna; las autoridades acertadamente evitan exacerbar la deflación y, con ello, el problema de la deuda. Una variación en la política cambiaria china tendría que ir acompañada de una flexibilización de los controles que permitiera la salida del país de un cierto volumen de ahorro; China registra una tasa de ahorro de casi $50 \%$.

Otros países asiáticos siguen la política cambiaria china y tampoco revalúan sus monedas; de hacerlo, sufrirían severas consecuencias en caso de un shock exógeno.

EUA espera que con el tiempo haya menos intervención en los mercados monetarios asiáticos y las monedas asiáticas se aprecien, en especial el yen y el renminbi, ya que $44 \%$ del déficit estadounidense deriva del comercio con Asia (China 21\%, ${ }^{15}$ Japón 15\%, Cuenca del Pacífico 8\%). ${ }^{16}$ La apreciación del yen se ha estado evitando con intervenciones en el mercado cambiario y por los débiles fundamentos económicos de Japón, aunque como ya se señaló, la economía de este país se está recuperando. Por otra parte, también ya se

13 A este respecto cabe señalar que México tenía un tipo de cambio fijo y grandes reservas monetarias internacionales (aunque no tan cuantiosas como las de China), justo antes de la crisis de 1994 1995; precisamente el tipo de cambio fijo contribuyó a la sobrevaluación del peso. La diferencia entre el caso mexicano y el chino es que China en lugar de permitir una sobrevaluación provoca una subvaluación que le permite colocar sus productos a precios bajos en los mercados inter nacionales.

14 La inflación en China es de sólo 0.7\%; en Corea del Sur, de 3\%. Japón empieza a salir de la deflación y Hong Kong enfrenta una deflación de $2.5 \%$. euA espera que en esos países se ajusten los tipos de cambio y los niveles de precios.

15 El superávit comercial chino con eUA fue cercano a 90 mmd en 2000 y se registra con un volumen de comercio mucho menor al que existe entre Japón y euA.

16 El resto se distribuye de la siguiente manera: eurozona 15\%, Canadá 11\%, México 9\%, opep 7\%, otros países europeos $5 \%$, otros $9 \%$. 
han visto las razones por las que no es probable que el renminbi chino no convertible se revalúe en un futuro cercano.

En este punto es útil referirse a la enorme acumulación de reservas monetarias internacionales en dólares por parte de Japón, China y otros países asiáticos. A medida que el dólar cae, los bancos centrales de esos países compran dólares baratos para mantener bajo el valor de sus respectivas divisas y protegerse de fluctuaciones en el valor del dólar. Con ello financian el déficit estadounidense y evitan que el dólar caiga aún más.

Sobre todo desde principios de 2002, los bancos centrales de los países mencionados han adquirido grandes cantidades de valores del Tesoro de EuA, que ascienden a más de 100 mil milllones de dólares. Los principales tenedores de esos activos son Japón, cuya recuperación económica depende en gran medida del crecimiento de las exportaciones (por lo que las tiene que hacer competitivas, manteniendo bajo el valor del yen) y China, que compra dólares para mantener fijo el tipo de cambio del renminbi en relación con el dólar y mantener sus ventajas competitivas en los mercados internacionales. Las economías asiáticas menores siguen la misma política en virtud de su estrecha relación con el dólar. Aunque no puede señalarse un límite para las reservas que puede acumular un país, el costo cada vez mayor que implica la tenencia de reservas, así como la creciente presión política de EUA y Europa, harán que en algún momento cese la acumulación de activos en dólares.

Resulta entonces que varios países de Asia, particularmente China, decidieron subvaluar sus tipos de cambio y exportar capital a EUA. Si bien es conveniente la acumulación de reservas para protegerse de futuras crisis, se ha llegado a una situación en la cual países con alto volumen de población pobre (excepto Japón), le están prestando al país más rico del mundo y a tasas de interés reales probablemente negativas. En vista de esto, el ex secretario del Tesoro estadounidense, Larry Summers, declaró que "la forma exagerada en que Japón, China y los países emergentes están financiando a EUA, plantea dudas sobre el buen funcionamiento del sistema" (FMI, 2004b: 48).

\section{Fluctuaciones en el valor del dólar}

Para muchos inversionistas, el dólar sigue siendo "tan bueno como el oro", aunque carece de la estabilidad que rigió bajo los acuerdos de Bretton Woods. La flexibilidad de los tipos de cambio ocurrió a costa de la estabilidad y la certidumbre. Importar o exportar productos conlleva el riesgo de que se modifique el tipo de cambio; lo mismo ocurre al invertir. Con el fin de limitar ese riesgo, comerciantes e inversionistas recurren a contratos de futuros y a otro tipo de transacciones. Aun así, pagando un costo por ella, la seguridad nunca es completa.

El valor del dólar se eleva y cae siguiendo un patrón cíclico. A consecuencia de un auge económico, se eleva durante un promedio de cinco años y luego cae por dos o tres 
Cuadro 1

Recientes ciclos del dólar y sus causas

a) ascendentes

1981-1985 Recortes fiscales de Reagan, auge económico

1995-2000 Auge económico por la "nueva economía"

b) a la baja

1985-1987 Déficit comercial

2001 a la fecha Déficit comercial, tasas de interés reales negativas.

Como fácilmente puede advertirse, se registraron dos periodos prolongados de crecimiento, alternados con dos periodos de recesión.

Fuente: Hormats, 2001.

años, debido a déficit comerciales o a una política monetaria expansiva (véase Cuadro 1). Al iniciarse los años ochenta, el fuerte incremento en el valor del dólar condujo a una desinflación y a una recesión severa pero corta; muchos exportadores estadounidenses perdieron sus mercados externos y hubo un rápido y doloroso ajuste en varias industrias estadounidenses que competían con las importaciones. Pero en 1985 se inició una depreciación; el dólar más competitivo (su tipo de cambio cayó más de 40\%) elevó las exportaciones, mejoró las perspectivas de la industria estadounidense y sirvió de base para un periodo de fuerte y sostenido crecimiento económico. La reestructuración corporativa de los años ochenta en EUA ayudó a sentar las bases del rápido crecimiento de los años noventa.

A fines de los noventa, el dólar se elevó a medida que los inversionistas huían de Asia, luego de Rusia y finalmente de Latinoamérica; el dinero fluyó a EuA como el lugar mejor y más seguro para los ahorros globales. La nueva oferta de dólares ayudó a financiar inversión y a cubrir el marcado deterioro en las cuentas con el exterior. El dólar más fuerte abarató las importaciones e hizo aún más competitivo el mercado estadounidense. Lo anterior facilitó al FED expandir la oferta monetaria, mantener bajas las tasas de interés y, por ende, una corriente de crédito a las empresas e individuos estadounidenses. Pero al mismo tiempo, el incremento en las importaciones obligó a hacer despidos en varios sectores manufactureros. ${ }^{17}$

La trascendencia de los cambios en el valor de las principales divisas obedece entre otras cosas al cuantioso movimiento diario de divisas en los mercados cambiarios mundiales, que es de alrededor de 1.25 billones de dólares. En virtud de la revolución en las

17 La evolución de la economía estadounidense a fines de los años noventa presenta un interesante acertijo o enigma a los economistas. A diferencia de los ciclos económicos (monetarios) en las dos décadas anteriores, el periodo de crecimiento acelerado en esos años no fue seguido rápidamente por un incremento importante en la inflación, por una política monetaria contraccionista ni por una reversión en la actividad real. En vez de ello, la inflación permaneció baja y las tasas de interés estables, el tipo de cambio del dólar se apreció y el capital fluyó a EUA, financiando un significativo deterioro en la balanza comercial. Además, la aceleración en la actividad real fue guiada por una aceleración en el crecimiento de la productividad (Hunt y Rebucci, 2003). 
comunicaciones, miles de millones de dólares se mueven de un país a otro con sólo accionar un botón. La facilidad e importancia de los mercados financieros mundiales atraen a un creciente número de participantes (bancos, instituciones financieras y especuladores individuales). De esas transacciones por 1.25 billones de dólares que se realizan a diario en el mercado cambiario mundial, muy pocas se relacionan con el comercio internacional ( $2.8 \%$ en 2000, comparadas con $3.6 \%$ en 1995); la mayoría son inversiones de portafolio $\mathrm{y}$ adquisiciones o fusiones transfronterizas. Como los mercados financieros han crecido mucho más rápidamente que el comercio internacional, por cada billón de dólares de comercio internacional hay muchos más billones de dólares de transacciones financieras.

A través de mercados de capital interrelacionados, a los ahorradores de un país les resulta fácil invertir en otro. Muchos inversionistas optan por inversiones a muy corto plazo que puedan mover rápidamente respondiendo a un cambio en las tasas de interés o en las percepciones de riesgo.

Otras razones de este crecimiento explosivo en el movimiento internacional de capital, es que los bancos centrales compran dólares como parte de las reservas que mantienen para liquidar las cuentas internacionales de su país o para dar estabilidad a sus respectivas monedas, tal como se ha visto que hacen algunos países asiáticos.

\section{En busca de una solución}

Sobre todo a partir de la última década del siglo xx, los mercados financieros a menudo reaccionan en exceso, esto es, registran fuertes fluctuaciones que elevan o bajan artificialmente el valor de una moneda, más allá de lo razonable de acuerdo a la situación económica del país en cuestión. El dólar, el euro y el yen frecuentemente están sobre o subvaluados, lo que perjudica a los países, sobre todo los subdesarrollados, con los que mantienen relaciones económicas.

En vista de esto, desde hace tiempo han surgido propuestas de mejorar la coordinación macroeconómica entre el G-3 (EUA, la UE y Japón) y serias discusiones acerca de establecer o no zonas meta entre las principales divisas, propuesta que está muy lejos de adoptarse.

Para recuperar parte de la relativa estabilidad que existió cuando rigieron el patrón oro o los tipos de cambio fijos, manteniendo al mismo tiempo las ventajas de la flexibilidad, Bergsten y Williamson (2003) aconsejan el "establecimiento de zonas meta entre las divisas clave (dólar, euro, yen)", basadas en las variables económicas fundamentales y ajustadas conforme a éstas cuando sea necesario.

Su propuesta contempla una amplia banda de flotación: 15\% hacia arriba y hacia abajo del nivel considerado de equilibrio. Por ejemplo, con una economía japonesa considerablemente más débil que la estadounidense, un margen de $15 \%$ pondría al yen alrededor de 100 o 105 por dólar, nivel en el que se había estado negociando hasta que a principios de 2001 empezó a debilitarse de nuevo. A fines de los años noventa, el yen estaba en su valor 
de equilibrio, al apreciarse alrededor de un tercio: de 150 por dólar en el verano de 1998 pasó a 100 a fines de 1999 .

Como se advierte, las zonas meta no significan un retorno a los tipos de cambio fijos sino que se asimilan a una especie de tipos de cambio flexibles y manejados. De hecho, siempre hay un manejo de los tipos de cambio, pues ningún país permanece impasible cuando sus monedas caen o se elevan más allá de ciertos límites.

Con el establecimiento de zonas meta creíbles, Bergsten y Williamson (2003) creen que se estabilizaría el sistema. Cuando los valores de las monedas se aproximaran a los límites de la zona, los participantes del mercado se darían cuenta de que habían llegado a los límites de una apreciación o de una depreciación y empezarían a especular con movimientos que harían volver la moneda a su valor de equilibrio. Como ejemplo está la intervención del Banco de Japón en 1995 para evitar que el yen se apreciara más allá de 80 por dólar; tras esto, el mercado se percató de que no habría una ulterior apreciación. Desde entonces el yen se ha depreciado. En 1998 intervino euA para evitar que el yen se depreciara más allá de 145 por dólar.

Las zonas meta pueden ser respaldadas por intervención esterilizada ${ }^{18}$ y Bergsten acepta que toda zona necesita reestructurarse atendiendo a cambios fundamentales, como una aguda elevación en el precio del petróleo o en los diferenciales de inflación.

Sin embargo, hay resistencia a adoptar zonas meta explícitas. Bergsten lo atribuye a que sin zonas meta explícitas que defender, cualquier movimiento en el tipo de cambio se atribuye a las fuerzas anónimas del mercado, lo que significa que no puede señalarse un culpable.

Sakakibara y otros expertos opinan que si las autoridades monetarias hicieran explícitas las zonas, éstas se tornarían vulnerables, pues se convertirían en metas atractivas para los especuladores. Él considera que la solución obvia es una flotación manejada; se opone a la flotación pura en la cual los gobiernos se abstienen de intervenir para estabilizar su

18 La intervención ocurre cuando un gobierno compra su propia moneda o una moneda extranjera a fin de modificar el tipo de cambio. Por ejemplo, cuando el banco central emite nuevos dólares o euros o yenes para comprar una moneda, incrementa la oferta monetaria total. La intervención es esterilizada cuando el banco central toma acciones para contrarrestar el incremento en la oferta monetaria interna, vendiendo bonos o tomando alguna otra acción compensadora; por ejemplo, si el FED compra dólares para manipular el tipo de cambio del dólar, podría vender bonos para conseguir que la cantidad de dinero en circulación permanezca sin cambio. Por el contrario, la intervención no esterilizada implica un cambio real en la oferta monetaria. Hay controversia acerca de qué tan efectivamente pueden los gobiernos intervenir en los mercados cambiarios para modificar los valores relativos del dólar, del euro y del yen. El enorme crecimiento de los mercados de capital globales en los últimos 20 años ha restado a la intervención considerable efectividad. En las condiciones actuales, Europa difícilmente intervendría unilateralmente en los mercados para hacer bajar al euro. El всE tiene sólo 50 mil millones de dólares en reservas a su disposición, cantidad insuficiente para intervenir. Los japoneses gastaron más del doble de esa cantidad en 2003 en sus intentos por bajar el valor del yen. 
moneda, algo que difícilmente ocurre. Cuando los mercados financieros llevan los valores de las monedas a niveles poco realistas, sea a la alza o a la baja, más allá de lo que justifican las variables económicas fundamentales, los gobiernos deben intervenir conjuntamente, esto es, con la participación de todos los países del G-3, y en forma masiva y decidida.

Al respecto, se percibe desinterés del G-7 en la situación cambiaria. Esto se puso de manifiesto en la declaración que siguió a la reunión de los ministros de Hacienda y gobernadores de los bancos centrales del G-7 (Boca Ratón, Florida, 7 de febrero de 2004); allí se señaló de manera tibia que los tipos de cambio deben corresponder a los fundamentos económicos y que el exceso de volatilidad y desorden en los movimientos de aquéllos perjudican el crecimiento económico. Recalcaron que para promover ajustes graduales y generales del sistema financiero internacional, basados en mecanismos de mercado, "conviene una mayor flexibilidad cambiaria en países o áreas económicamente importantes, que aun carecen de esa flexibilidad" (FMI, 2004b). Esto, en clara alusión a la UE y a Asia, sobre todo a Japón y China.

\section{Consideraciones finales}

Los déficit fiscal y comercial de euA han inundado al mundo de dólares, lo que ha servido para estimular los negocios en escala mundial. Pero como contrapartida, este país es por mucho el mayor deudor mundial, con las consecuencias que se han delineado a lo largo de este trabajo.

No obstante, el dólar mantiene su primacía como moneda de comercio y de reserva internacional. Debido a que Europa aún no tiene un mercado de valores plenamente integrado, el dólar sigue dominando también la negociación mundial de valores, aunque crece la participación europea.

Su prominencia ha traído a EuA claros beneficios. Cada país deriva ganancias del señoreaje (la diferencia entre el costo de imprimir o acuñar la moneda nacional y lo que ésta comprará en términos de bienes y servicios reales). Para adquirir dólares, los inversionistas extranjeros tienen que vender bienes, servicios o activos a los estadounidenses. Si esos inversionistas mantienen la moneda como reserva, la usan para financiar transacciones o mantienen los dólares como una inversión de hecho, efectúan un préstamo a muy bajo interés a los individuos u organizaciones estadounidenses. Por tener la moneda líder en el nivel global, EuA se beneficia de una especie de super señoreaje (Hughes, 2001).

En varios países existe la idea de terminar la dependencia respecto al dólar, pero no se ve la manera de lograrlo.

Para empezar sería lógico que EUA enfrentara una fuerte presión internacional para disminuir sus desequilibrios fiscales y comerciales, pero no es así. Por el contrario, EUA presiona a otros países para que ellos efectúen el ajuste; en tanto no exista una decisiva política para sanear la economía estadounidense, habrá tensiones monetarias y financieras internacionales. 
Los desequilibrios mundiales deben corregirse de manera ordenada. Los tipos de cambio pueden contribuir a ello, ya que la estabilidad cambiaria trae consigo incrementos en el comercio, la inversión y la producción; lograr esa estabilidad requiere aumentar el ahorro nacional en EUA y reforzar el potencial de crecimiento en Europa y Japón. Alemania y Francia, en particular, tienen mucho que hacer para estimular el crecimiento económico, incrementando la productividad, mejorando la eficiencia de los servicios públicos y reduciendo los déficit presupuestales.

Una caída del dólar afectaría la débil recuperación económica europea conducida por el sector exportador. Se perderían también los mercados internos en vista de que resultarían muy baratas las importaciones procedentes de EUA, lo que erosionaría las ganancias empresariales y dañaría el crecimiento económico además de aumentar el desempleo. Todo esto haría más tensas las relaciones económicas entre euA y la uE.

Funcionarios estadounidenses esperan que Europa responda a la depreciación del dólar desregulando su economía. Muchas empresas europeas quieren que eso pase y están presionando a sus gobiernos para que adopten reformas estructurales de gran alcance; no obstante, es poco probable que ello ocurra, pues fuertes sectores de su población, en especial los sindicatos, se oponen a las reformas. En cualquier caso, pasarían años antes de que los cambios estructurales empezaran a surtir efecto positivo.

Los países del Medio Oriente que exportan petróleo y gas en dólares y realizan cuantiosas importaciones de Europa, saldrán perdiendo. Otro tanto puede decirse de Rusia, pues también gran parte de sus ingresos son en dólares y sus egresos, en euros (Hanna, 2003).

China, que ha emergido como potencia económica global, se beneficiaría de un dólar más débil, pues atraería más inversión. Posiblemente ésta pase de 57 mmd en 2003 a 150 mmd en 2004 (The Economist, 2004). China podría encontrar difícil absorber tanto dinero, y ante tan fuertes entradas de capital a China, existe la posibilidad de que los países vecinos inicien una perjudicial ronda de devaluaciones competitivas. Como ya se ha visto, ese país está siendo presionado para flexibilizar el vínculo entre su moneda y el dólar.

En EuA una baja en el valor del dólar implicará crecimiento más bajo, menos consumo, menos inversión, más exportaciones y menos importaciones, todo ello como parte del ajuste. Esto exacerbará el dilema fiscal en EuA, acarreando tasas de interés más altas y precios accionarios más débiles.

La declinación del dólar empieza a privar a EuA de sus fuentes de financiamiento; al debilitarse esa divisa, los inversionistas adquieren menos valores estadounidenses o incluso se deshacen de los que poseen. Por eso el capital extranjero demandará rendimientos cada vez más altos sobre sus inversiones en dólares para contrarrestar el riesgo cambiario. Pero los incrementos en las tasas de interés no necesariamente convencerán a los inversionistas de arriesgarse a invertir en un dólar que se debilita. Si los inversionistas se deshacen de sus activos en dólares, hay riesgo de que esa divisa caiga abruptamente, trayendo precios al alza y presiones para que el FED revierta su política y eleve las tasas de interés. 
El gobierno de EuA debe trabajar por una declinación gradual en el valor internacional del dólar. Cambios en éste afectan las industrias de exportación y las industrias que compiten con las importaciones. Lo mismo es verdad para las industrias de países cuya moneda está vinculada al dólar.

Los países emergentes encontrarán más difícil atraer capital. La depreciación ya ha tenido efectos en muchos socios comerciales de EUA, cuyos exportadores han visto reducir severamente sus ganancias y el desempleo empieza a crecer. Cuando el dólar se deprecia, lo mismo ocurre a las monedas de esos países.

La debilidad del dólar acentúa la incertidumbre y plantea un reto a la gestión macroeconómica de los socios comerciales de EuA. Aunque la depreciación está bajando gradualmente el gran déficit en cuenta corriente de EUA, si se debilita más la actitud de los inversionistas y hay turbulencia en el mercado bursátil, podría haber repercusiones adversas interna y externamente.

Cabe señalar que la caída del dólar es menor frente a otras monedas, en particular las latinoamericanas, incluido el peso mexicano. Es más, respecto a éste, el dólar se está apreciando, lo que significa que la moneda mexicana se debilita frente al dólar, que a su vez a nivel mundial se está depreciando; esto afecta severamente la relación comercial de México con la Unión Europea.

Aunque, como se ha visto, el dólar ha registrado varias bajas en su valor desde el establecimiento de la flotación cambiaria, los niveles récord que ha alcanzado la deuda externa de EUA llevan a pensar que la economía mundial podría estar entrando en terrenos peligrosos, más allá de los grandes riesgos para los mercados financieros. La debilidad del dólar continuará hasta que el déficit en cuenta corriente y la deuda externa de EUA alcancen niveles sostenibles y dejen de ser una amenaza para la recuperación mundial. Todo augura problemas para el dólar; sobre todo si como parece, continúa incrementándose el gasto militar estadounidense.

\section{Bibliografía}

Banco Mundial, Informe sobre el Desarrollo Mundial, Washington, Banco Mundial, 2003.

Bergsten, C. Fred, "A Framework for Fluctuations: Target Zones for the Major Currencies", The Currency Conundrum, reunión organizada por el Woodrow Wilson Center (11 de enero), en línea, 2001.

y John Williamson, Dollar Overvaluation and the World Economy, Washington, Instituto de Economía Internacional, 2003.
Bernard, Jean-René, El euro cinco años después, Conferencia, ITAM, 11 de marzo, 2004.

Bordo, Michael D., "Exchange rate regime choice in historical perpective", Working Paper 03/160, Washington, FMI, 2003.

Bowles, Samuel, La economía del despilfarro, Madrid, Alianza, 1989.

Chapoy Bonifaz, Alma, Hacia un nuevo sistema monetario internacional, México, Miguel Ángel Porrúa, 1998a. 
, "Repercusiones de la introducción del euro", en Mántey, Guadalupe y Noemí Levy (comps.) Desorden monetario mundial y su impacto en el sistema financiero mexicano, México, UNAMDGAPA-ENEP Acatlán, 1998b.

,"Metas explícitas de inflación como esquema para conducir la política monetaria. El caso de México", en prensa, 2004.

Fischer, Stanley, "Exchange rate regimes: is the bipolar view correct?", Journal of Economic Perspectives, vol. 50, núm. 2, Verano, 2001.

FMI, Informe anual, Washington, FMI, 2003.

, Boletín, 25 de agosto, vol. 32, núm. 15, Washington, FMI, 2003a.

, Boletín, 22 de diciembre vol. 32, núm. 23. Washington, FMI, 2003b.

, Government Finance, Washington, FMI, 2003c.

, Boletín, 9 de febrero, vol. 31, Washington, FMI, 2004a.

, Boletín, 23 de febrero, vol. 31, Washington, FMI, 2004b.

, International Financial Statistics, varias ediciones, Washington, FMI.

Hanna, Daniel, "The Impact of a Weaker Dollar on the Gulf', 9 de diciembre, 2003, www.ameinfo. com

Hormats, Robert, "The destiny of the dollar", The Currency Conundrum, reunión organizada por el Woodrow Wilson Center (11 de enero), en línea, 2001.

Hughes, Kent, "Challenges for America", The Currency Conundrum, Reunión organizada por el Woodrow Wilson Center (11 de enero), en línea, 2001.

Hunt, Benjamin y Alessandro Rebucci, "The U.S. dollar and the trade deficit: what accounts for the late 1990s?", Working Paper 03/194, Washington, FMI, 2003.

Micco, Alejandro, Ernesto Stein y Guillermo Ordóñez, "The currency union effect on trade: early evidence from the European Union", Economic policy, núm. 37, octubre, 2003.

Platt, Gordon, "Foreign Exchange", Global Finance (varias ediciones), Nueva York, Global Finance Media, Inc.

Sakakibara, Eisuke, "The Yen: Looking for Confidence and the Consumer", The Currency Conundrum, reunión organizada por el Woodrow Wilson Center (11 de enero), en línea, 2001.

Sarbanes, Paul, "Trade and current account deficits", The Currency Conundrum, reunión organizada por el Woodrow Wilson Center (11 de enero), en línea, 2001.

Scherer, Ron, The Christian Science Monitor, 9 de enero, 2004, http://Www.csmonitor.com

The Economist, "Behind the Mask. A survey of business in China", 20 de marzo, 2004.

-, "Military Strategy. The Next American Empire", 20 de marzo, 2004.

The Wall Street Journal on line, http://online.wsj.com, Varias ediciones.

Walter, Norbert, "Euro Euphoria", The Currency Conundrum, reunión organizada por el Woodrow Wilson Center (11 de enero), en línea, 2001. 